\title{
INFILTRAÇÃO DE ÁGUA NO SOLO SOB ESCARIFICAÇÃO E ROTAÇÃO DE CULTURAS ${ }^{(1)}$
}

\author{
Maryara Buriola Prando(2), Dácio Olibone ${ }^{(3)}$, Ana Paula Encide \\ Olibone $^{(3)} \&$ Ciro Antonio Rosolem ${ }^{(4)}$
}

\begin{abstract}
RESUMO
Nos solos com restrições físicas e, ou, físico-hídricas ao crescimento de raízes, aumentar o potencial de armazenagem de água por meio de melhorias na infiltração pode ser uma estratégia viável para aumento da produtividade das culturas. Nesse sentido, este trabalho teve como objetivo avaliar a infiltração de água em um Nitossolo Vermelho distrófico, com três sistemas de rotação de culturas sob semeadura direta com e sem escarificação inicial. $O$ sistema de rotação de culturas constou de: (1) milheto/soja/sorgo/milho/sorgo (M/S/So/Mi/So), (2) milheto/soja/ Brachiaria ruziziensis/milho/Brachiaria ruziziensis $(\mathrm{M} / \mathrm{S} / \mathrm{B} / \mathrm{Mi} / \mathrm{B})$ e (3) milheto/ soja/Brachiaria ruziziensis + mamona/milho/Brachiaria ruziziensis + mamona $(\mathrm{M} /$ $\mathrm{S} / \mathrm{B}+\mathrm{Ma} / \mathrm{Mi} / \mathrm{B}+\mathrm{Ma})$. A infiltração de água no solo foi avaliada em campo com anéis concêntricos instalados na superfície, a 0,10 e 0,20 m de profundidade, em $2006 \mathrm{e}$ 2007. Após o primeiro ano, o manejo com escarificação inicial do solo apresentou a maior infiltração de água. A rotação Brachiaria ruziziensis + mamona proporcionou maior infiltração da água no solo. A atividade do sistema radicular das espécies nas parcelas sem escarificação inicial aumentou a velocidade de infiltração da água no solo.
\end{abstract}

Termos de indexação: compactação do solo, resistência à penetração, movimento da água, semeadura direta.

(1) Apoio financeiro da FAPESP. Recebido para publicação em julho de 2009 e aprovado em fevereiro de 2010.

(2) Graduanda pela Faculdade de Ciências Agronômicas, Universidade Estadual Paulista - UNESP. Caixa Postal 237, CEP 18610307 Botucatu (SP). E-mail: maryprando@yahoo.com.br

(3) Doutorando, Departamento de Produção Vegetal, Faculdade de Ciências Agronômicas, UNESP. E-mails: olibone@fca.unesp.br; encide@fca.unesp.br

(4) Professor Titular, Departamento de Produção Vegetal da Faculdade de Ciências Agronômicas, UNESP. E-mail: rosolem@fca.unesp.br 


\title{
SUMMARY: WATER INFILTRATION IN SOIL AS INFLUENCED BY CHISELING AND CROP ROTATIONS
}

\begin{abstract}
In soils with physical and/or physical hydric restrictions for root growth, it may be a viable strategy to increase crop productivity by increasing water storage potential through improvements in water infiltration. Accordingly, the objective of this study was to determine water infiltration in a Hapludult in three crop rotations under no-tillage, with and without initial chiseling. Crop rotations consisted of: millet/soybean/sorghum/maize/sorghum; millet/soybean/Brachiaria ruziziensis/corn/Brachiaria ruziziensis; and millet/soybean/ Brachiaria ruziziensis + castor bean/corn/Brachiaria ruziziensis + castor bean. Water infiltration in soil was evaluated in the field, using concentric discs at the soil surface and at depths of 0.10 and $0.20 \mathrm{~m}$, in 2006 and 2007. After the first year, chiseling led to increased infiltration of water into the soil. Water infiltration was greatest in the crop rotation system with Brachiaria ruziziensis + castor bean. The activity of root systems of crops in the plots without chiseling increased the rate of water infiltration into the soil.
\end{abstract}

Index terms: soil compaction, penetration resistance, water movement, no-tillage.

\section{INTRODUÇÃO}

O Brasil destaca-se mundialmente por suas extensas áreas cultivadas em sistemas altamente mecanizados e com intenso uso do solo, muitas vezes sob condições de elevada umidade (Silva et al., 2002), o que favorece o aparecimento do fenômeno de compactação (Horn et al., 2003), comprometendo diretamente a capacidade de infiltração (Secco et al., 2004; Lanzanova, et al., 2007), o armazenamento de água do solo e o crescimento de raízes (Derpsch et al., 1991; Dias Júnior \& Pierce, 1996; Tavares Filho \& Tessier, 1998; De Maria et al., 1999; Bertol et al., 2001). Essas alterações físico-hídricas podem interferir negativamente na produtividade das culturas, especialmente em regiões onde são comuns a restrição e a má distribuição das chuvas (veranicos). Dessa forma, os diferentes sistemas de manejo de solos têm a finalidade de reduzir essas restrições, propiciando condições favoráveis ao desenvolvimento das culturas. $\mathrm{O}$ método mais tradicional e mais adotado de manejo dessas condições desfavoráveis é aquele em que se utilizam hastes para realizar a movimentação e o rompimento das camadas compactadas, embora a operação envolva alto gasto energético e um longo período para sua execução (Jorge, 1985; Vernetti Junior \& Gomes 1999; Câmara \& Klein, 2005a). Câmara \& Klein (2005b) destacam o incremento na capacidade de infiltração que uma escarificação pode ocasionar em áreas com o sistema de semeadura direta.

A adoção do sistema de semeadura direta como alternativa, seguido de rotação de culturas, pode reduzir a intensidade do problema, pois o uso de plantas com sistema radicular vigoroso, que consigam se desenvolver em solos compactados, já é uma prática que tem apresentado resultados satisfatórios (Stone \& Silveira, 2001; Silva \& Rosolem, 2002; Abreu et al., 2004). Esse efeito deve-se à conjunção de fatores como proteção do solo mediante cobertura viva ou morta, maior retenção de água, efeito rizosférico das culturas, maior disponibilidade de matéria orgânica e melhores condições físicas do solo (Séguy \& Bouzinac, 1995). Pelo exposto, a adoção de sistemas de rotação com diferentes espécies e o manejo diferenciado do solo podem resultar em melhorias no armazenamento e na disponibilidade de água às plantas. Nesse sentido, determinadas espécies podem apresentar sistema radicular capaz de melhorar a infiltração de água no solo por meio do aumento em tamanho e na quantidade de bioporos verticais (Lal \& Vandoren, 1990).

O objetivo do presente trabalho foi determinar a taxa de infiltração de água de um Nitossolo Vermelho com três sistemas de rotação de culturas, sob área em sistema de semeadura direta com e sem escarificação inicial.

\section{MATERIAL E MÉTODOS}

O experimento foi instalado na Fazenda Experimental Lageado, Faculdade de Ciências Agronômicas, UNESP, Botucatu, SP, em Nitossolo Vermelho textura argilosa, com relevo plano a suave ondulado (Santos et al., 2006). A localização da área é definida pelas coordenadas geográficas: $22^{\circ} 49^{\prime}$ de latitude sul e $48^{\circ} 25^{\prime}$ de longitude oeste de Greenwich, com altitude média de $770 \mathrm{~m}$ e clima $\mathrm{Cfa}$, pela classificação de Köppen, caracterizado como subtropical úmido; a precipitação pluvial média anual fica em torno de $1.514 \mathrm{~mm}$, com temperatura média do mês mais quente superior a $23,3{ }^{\circ} \mathrm{C}$, e a do mês mais frio, de $17,1^{\circ} \mathrm{C}$.

A área experimental havia sido anteriormente cultivada com soja/milho e aveia-preta/milheto em 
sistema de semeadura direta durante cinco anos e inicialmente apresentou valores de densidade de 1,68, 1,74 e $1,75 \mathrm{~kg} \mathrm{dm}^{-3}$ para as camadas de 0,00-0,05, 0,05-0,10 e 0,10-0,20 m, respectivamente. O delineamento experimental foi o de blocos ao acaso em parcelas subdivididas, com quatro repetições. Nas parcelas principais foram estabelecidos os tratamentos em sistema de semeadura direta e com escarificação; nas subparcelas foram utilizados três sistemas de rotação: (1) milheto/soja/sorgo/milho/sorgo; (2) milheto/ soja/Brachiaria ruziziensis/milho/Brachiaria ruziziensis; (3) milheto/soja/Brachiaria ruziziensis + mamona/ milho/Brachiaria ruziziensis + mamona. A escarificação foi feita usando um escarificador com sete hastes, espaçadas de $0,5 \mathrm{~m}$, e profundidade de ação de $0,3 \mathrm{~m}$ e rolo destorroador, antecedendo a semeadura do milheto, em agosto de 2005.

A semeadura do milheto ADR 500 foi realizada no dia 13/09/2005 com $40 \mathrm{~kg} \mathrm{ha}^{-1}$ de sementes e germinação de $90 \%$, em linhas espaçadas de 0,17 m, sem a adição de fertilizantes. Aos 65 dias após a emergência (DAE), fez-se a dessecação química das plantas com herbicida pós-emergente não seletivo glyphosate (dose de $720 \mathrm{~g} \mathrm{ha}^{-1}$ i.a.), aplicado com pulverizador de barras motomecanizado, em volume de calda de $120 \mathrm{~L} \mathrm{ha}^{-1}$.

Após uma semana, semeou-se a soja, cultivar Embrapa 48, em linhas espaçadas de 0,45 m, com 18 sementes $\mathrm{m}^{-1}$ e adubação de $400 \mathrm{~kg} \mathrm{ha}^{-1}$ da fórmula 00-20-20.

A Brachiaria ruziziensis foi sobressemeada na cultura da soja em estádio fisiológico R5, considerando a quantidade de sementes de 600 pontos de valor cultural (V.C.) ha-1, sendo distribuídas manualmente na superfície do solo em linhas individuais, para evitar a barreira proporcionada pelas folhas da cultura da soja.

Após a colheita da soja, sobre a Brachiaria ruziziensis semeou-se a mamona, cultivar Lyra, em linhas espaçadas de $0,45 \mathrm{~m}$ e 3,8 sementes $\mathrm{m}^{-1}$. Também foi semeado o sorgo, híbrido Pionner 8118 , em linhas de $0,45 \mathrm{~m}$ com 8 sementes $\mathrm{m}^{-1}$, ambos sem adubação.

Em dezembro de 2006, após o manejo químico dessas plantas, realizou-se a semeadura do milho, DOW 712, com 6 sementes $\mathrm{m}^{-1}$ a $0,90 \mathrm{~m}$ entre linhas e adubação de $350 \mathrm{~kg} \mathrm{ha}^{-1}$ da fórmula 8-28-16 aplicada no sulco de semeadura. Aos 20 e 35 DAE, foram aplicados em cobertura $60 \mathrm{~kg} \mathrm{ha}^{-1}$ de N (Ureia).

As sementes de Brachiaria ruziziensis foram semeadas junto ao milho, sendo adicionadas à caixa de adubo, na proporção de $20 \%$ do peso de adubo. Após a colheita do milho, foram semeados o sorgo e a mamona em seus respectivos tratamentos, da mesma forma descrita no ano anterior.

A produtividade de massa de matéria seca das plantas de cobertura (milheto, sorgo e Brachiaria ruziziensis) foi avaliada em outubro de 2006 e 2007, tomando-se aleatoriamente três amostras por parcela na área de um quadrado de madeira de $0,25 \mathrm{~m}^{2}$. Na mesma época, foram coletadas amostras de solo nas camadas de $0,00-0,05,0,05-0,10$ e $0,10-0,20 \mathrm{~m}$ para avaliação da massa de matéria seca radicular, sendo coletadas quatro subamostras aleatórias em cada subparcela, com trado coletor de raízes (diâmetro interno de 0,07 m). Após a coleta, o solo foi lavado com água e as raízes, depois de separadas, foram colocadas em sacos de papel e secas em estufa de aeração forçada a $65^{\circ} \mathrm{C}$ por $48 \mathrm{~h}$, para determinação da massa de matéria seca radicular.

A taxa de infiltração de água no solo foi avaliada em outubro de 2006 e 2007, utilizando-se anéis duplos concêntricos, conforme método descrito por Forsythe (1975), instalados na superfície, a 0,10 e a $0,20 \mathrm{~m}$ de profundidade. Os anéis foram confeccionados com 0,15 e 0,30 m de diâmetro interno e 0,25 m de altura. $\mathrm{O}$ volume de água inicial foi de 3,53 L e mantido com variação máxima de $5 \%$ da inicial com o uso de um frasco plástico graduado acoplado ao anel interno. A carga hidráulica do anel externo foi mantida manualmente no mesmo nível do anel interno.

As avaliações foram realizadas com a umidade do solo entre 140 e $160 \mathrm{~g} \mathrm{~kg}^{-1}$, determinada pelo método gravimétrico. Para avaliação da taxa de infiltração a 0,10 e 0,20 $\mathrm{m}$ de profundidade, foram removidas as camadas de solo acima da referida camada estudada e instalados os discos concêntricos.

Após obtenção de três repetições de leitura de infiltração de água com variação entre elas menor que $10 \%$, suspendeu-se o processo, considerando que nesse momento havia sido atingida a taxa de infiltração constante. O tempo para obtenção da taxa constante variou de 90 a $125 \mathrm{~min}$.

Com os resultados da lâmina de água acumulada no solo (I), em função do tempo de infiltração (t), obtiveram-se, por regressão, os parâmetros (k e n) da equação de Kostiakov (1932) $\left(\mathrm{I}=\mathrm{k} \cdot \mathrm{t}^{\mathrm{n}}\right)$. A taxa de infiltração da água no solo (VI $=\mathrm{knt}^{\mathrm{n}-1}$ ) foi obtida derivando-se a equação da lâmina acumulada em relação ao tempo $(\mathrm{VI}=\mathrm{dI} / \mathrm{dt})$.

\section{RESULTADOS E DISCUSSÃO}

\section{Primeiro ano de experimento}

A velocidade de infiltração de água no solo foi maior nos tratamentos com escarificação inicial, comparada aos mesmos tratamentos sem escarificação (Quadro 1). Para a camada superficial do solo submetido à escarificação inicial, foram observados valores superiores de infiltração inicial - aquela referente ao primeiro minuto após iniciado o processo de infiltração $\left(68 \mathrm{~cm} \mathrm{~h}^{-1}\right)$ - e de constante de infiltração $\left(38 \mathrm{~cm} \mathrm{~h}^{-1}\right)$, comparados ao tratamento sem escarificação (47 e $24 \mathrm{~cm} \mathrm{~h}^{-1}$, respectivamente). 
Quadro 1. Velocidade de infiltração inicial e constante de água em diferentes perfis do solo sob sistemas de manejo do solo e rotação de culturas, em 2006

\begin{tabular}{|c|c|c|c|c|}
\hline \multirow{4}{*}{$\begin{array}{l}\text { Sistema } \\
\text { de rotação }\end{array}$} & \multicolumn{4}{|c|}{ Velocidade de infiltração de água $\left(\mathrm{cm} \mathrm{h}^{-1}\right)$} \\
\hline & \multirow{2}{*}{\multicolumn{2}{|c|}{$\frac{\text { Inicial }}{\text { Escarificação }}$}} & \multirow{2}{*}{\multicolumn{2}{|c|}{$\frac{\text { Constante }}{\text { Escarificação }}$}} \\
\hline & & & & \\
\hline & Com & Sem & Com & Sem \\
\hline & \multicolumn{4}{|c|}{ Superfície } \\
\hline M/S/So & $50 \mathrm{bA}$ & $50 \mathrm{aA}$ & $30 \mathrm{bA}$ & $22 \mathrm{bA}$ \\
\hline $\mathrm{M} / \mathrm{S} / \mathrm{B}$ & $51 \mathrm{bA}$ & $56 \mathrm{aA}$ & $31 \mathrm{bA}$ & $29 \mathrm{aA}$ \\
\hline $\mathrm{M} / \mathrm{S} / \mathrm{B}+\mathrm{Ma}$ & $104 \mathrm{aB}$ & $34 \mathrm{bB}$ & $53 \mathrm{aA}$ & $20 \mathrm{bB}$ \\
\hline \multirow[t]{2}{*}{ Média } & $68 \mathrm{~A}$ & $47 \mathrm{~B}$ & $38 \mathrm{~A}$ & $24 \mathrm{~B}$ \\
\hline & \multicolumn{4}{|c|}{$0,10 \mathrm{~m}$} \\
\hline M/S/So & $32 \mathrm{bA}$ & $46 \mathrm{aA}$ & $20 \mathrm{bA}$ & $15 \mathrm{aA}$ \\
\hline $\mathrm{M} / \mathrm{S}$ & $44 \mathrm{bA}$ & $47 \mathrm{aA}$ & $23 \mathrm{bA}$ & $18 \mathrm{aA}$ \\
\hline $\mathrm{M} / \mathrm{S} / \mathrm{B}+\mathrm{Ma}$ & $91 \mathrm{aA}$ & $46 \mathrm{aB}$ & $34 \mathrm{aA}$ & $15 \mathrm{aB}$ \\
\hline Média & $57 \mathrm{~A}$ & $46 \mathrm{~B}$ & $26 \mathrm{~A}$ & $16 \mathrm{~B}$ \\
\hline & \multicolumn{4}{|c|}{$0,20 \mathrm{~m}$} \\
\hline M/S/B & $\begin{array}{l}68 \mathrm{DA} \\
85 \mathrm{bA}\end{array}$ & $44 \mathrm{bB}$ & $\begin{array}{l}26 \mathrm{aA} \\
25 \mathrm{aA}\end{array}$ & $12 \mathrm{bB}$ \\
\hline $\mathrm{M} / \mathrm{S} / \mathrm{B}+\mathrm{Ma}$ & $103 \mathrm{aA}$ & $78 \mathrm{aB}$ & $20 \mathrm{bA}$ & $24 \mathrm{aA}$ \\
\hline Média & $85 \mathrm{~A}$ & $58 \mathrm{~B}$ & $23 \mathrm{~A}$ & $15 \mathrm{~B}$ \\
\hline
\end{tabular}

(1) M/S/SO: milheto/soja/sorgo; M/S/B: milheto/soja/Brachiaria ruziziensis; M/S/B+Ma: milheto/soja/Brachiaria ruziziensis + mamona. Médias seguidas por letras iguais, maiúsculas na linha e minúsculas na coluna, não diferem entre si pelo teste $t$ (LSD) a $5 \%$.

Esse comportamento é observado no tratamento sem escarificação inicial porque a densidade do solo tende a aumentar na superfície devido às pressões exercidas pelos veículos em condições de alta umidade, originando uma força externa que causa reorganização das suas partículas, as quais passam a ocupar menor volume (Silva et al., 2002; Horn et al., 2003; Lanzanova et al., 2007).

À medida que aumenta a compactação do solo, há redução da porosidade total e aumento da densidade e resistência do solo à penetração (Moraes et al., 1995; Borges et al., 1999), causando impedimento físico ao desenvolvimento do sistema radicular e restringindo o movimento da água e do ar ao longo do perfil (Jorge, 1985). No entanto, há relatos de que o sistema de semeadura direta, quando não compactado, resulta em taxas de infiltração superiores às do cultivo convencional, pois se baseia no não revolvimento do solo e na manutenção da superfície protegida com restos de resíduos culturais (Sidiras et al., 1982; Chang \& Lindwall, 1992; Benjamin, 1993; Resck, 1999), especialmente por apresentarem maior estabilidade de agregados e pela formação de bioporos verticais (Lal \& Vandoren, 1990).

A compactação do solo reduz a capacidade de infiltração de água e aumenta o risco de erosão, de déficit hídrico e desbalanço nutricional dos solos às plantas (Rosolem et al., 1994), resultando em crescimento mais superficial das raízes (Moraes et al., 1995; Muller et al., 2001), fato que foi observado em todas as rotações no solo sem escarificação (Quadro 2).

A taxa de infiltração inicial na camada superficial não apresentou diferença significativa entre as rotações M/S/So e M/S/B (50 e $51 \mathrm{~cm} \mathrm{~h}^{-1}$, respectivamente) no sistema com escarificação (Quadro 1). Na rotação M/ $\mathrm{S} / \mathrm{B}+\mathrm{Ma}\left(104 \mathrm{~cm} \mathrm{~h}^{-1}\right)$ em solo escarificado, a velocidade inicial de infiltração foi significativamente maior, fato que pode ser atribuído à maior quantidade de massa de matéria verde de Brachiaria ruziziensis + mamona, comparada à rotação $\mathrm{M} / \mathrm{S} / \mathrm{B}$, que continha Brachiaria ruziziensis solteira, e à maior produtividade de massa de matéria seca radicular no perfil do solo na rotação M/S/B+Ma (Quadro 2).

A taxa de infiltração constante para a camada superficial não apresentou diferença significativa entre as rotações $\mathrm{M} / \mathrm{S} / \mathrm{So}$ e M/S/B (30 e $31 \mathrm{~cm} \mathrm{~h}^{-1}$, respectivamente) no sistema escarificado (Quadro 1). Quando o solo foi escarificado, a constante de infiltração foi maior para a rotação $\mathrm{M} / \mathrm{S} / \mathrm{B}+\mathrm{Ma}\left(53 \mathrm{~cm} \mathrm{~h}^{-1}\right)$. Esses resultados mostram que o sistema com Brachiaria ruziziensis + mamona promove melhoria no tamanho e número de bioporos (canais formados pelas raízes) e provavelmente na diminuição da resistência do solo à penetração. Cunha et al. (2004) verificaram que a

Quadro 2. Produtividade de matéria seca da parte aérea e radicular de plantas de cobertura, em 2006

\begin{tabular}{|c|c|c|c|}
\hline \multirow{2}{*}{$\begin{array}{l}\text { Sistema } \\
\text { de rotação(1) }\end{array}$} & \multicolumn{2}{|c|}{ Escarificação } & \multirow{2}{*}{ Média } \\
\hline & Com & Sem & \\
\hline \multicolumn{4}{|c|}{ Massa de matéria seca da parte aérea $\left(\mathrm{kg} \mathrm{ha}^{-1}\right)$} \\
\hline M/S/So & $2134 \mathrm{cA}$ & $1445 \mathrm{cB}$ & $1789 \mathrm{c}$ \\
\hline $\mathrm{M} / \mathrm{S} / \mathrm{B}$ & $4668 \mathrm{bA}$ & $3958 \mathrm{bB}$ & $4313 \mathrm{~b}$ \\
\hline $\mathrm{M} / \mathrm{S} / \mathrm{B}+\mathrm{Ma}$ & 5848 aA & $4361 \mathrm{aA}$ & $5104 \mathrm{a}$ \\
\hline Média & $4216 \mathrm{~A}$ & $3255 \mathrm{~B}$ & - \\
\hline & \multicolumn{3}{|c|}{$\begin{array}{l}\text { Massa de matéria seca radicular }\left(\mathrm{kg} \mathrm{ha}^{-1}\right) \\
0,00-0,05 \mathrm{~m}\end{array}$} \\
\hline M/S/So & 285 & 280 & 283 \\
\hline $\mathrm{M} / \mathrm{S} / \mathrm{B}$ & 350 & 355 & 352 \\
\hline $\mathrm{M} / \mathrm{S} / \mathrm{B}+\mathrm{Ma}$ & 455 & 595 & 525 \\
\hline Média & 365 & 410 & - \\
\hline & \multicolumn{3}{|c|}{$0,05-0,10 \mathrm{~m}$} \\
\hline M/S/So & $325 \mathrm{bA}$ & $150 \mathrm{bB}$ & $240 \mathrm{~b}$ \\
\hline $\mathrm{M} / \mathrm{S} / \mathrm{B}$ & $295 \mathrm{bA}$ & $245 \mathrm{abA}$ & $270 \mathrm{~b}$ \\
\hline $\mathrm{M} / \mathrm{S} / \mathrm{B}+\mathrm{Ma}$ & $570 \mathrm{aA}$ & $335 \mathrm{aB}$ & $450 \mathrm{a}$ \\
\hline Média & $395 \mathrm{~A}$ & $245 \mathrm{~B}$ & - \\
\hline & \multicolumn{3}{|c|}{$0,10-0,20 \mathrm{~m}$} \\
\hline M/S/So & $170 \mathrm{bA}$ & $140 \mathrm{aA}$ & $155 \mathrm{~b}$ \\
\hline $\mathrm{M} / \mathrm{S} / \mathrm{B}$ & $230 \mathrm{bA}$ & $150 \mathrm{aB}$ & $190 \mathrm{~b}$ \\
\hline $\mathrm{M} / \mathrm{S} / \mathrm{B}+\mathrm{Ma}$ & $470 \mathrm{aA}$ & $230 \mathrm{aB}$ & $350 \mathrm{a}$ \\
\hline Média & $290 \mathrm{~A}$ & $170 \mathrm{~B}$ & - \\
\hline
\end{tabular}

(1) M/S/SO: milheto/soja/sorgo; M/S/B: milheto/soja/Brachiaria ruziziensis; $\mathrm{M} / \mathrm{S} / \mathrm{B}+\mathrm{Ma}$ : milheto/soja/Brachiaria ruziziensis + mamona. Médias seguidas por letras iguais, maiúsculas na linha e minúsculas na coluna, não diferem entre si pelo teste $t$ (LSD) a $5 \%$. 
resistência mecânica do solo à penetração é alterada pela ação radicular de Brachiaria ruziziensis em sistemas de rotação de culturas, apresentando menores valores de resistência à penetração $(2,30 \mathrm{a}$ $2,71 \mathrm{MPa}$ ) na profundidade de 0,15 a $0,35 \mathrm{~m}$, contra 2,93 a 3,28 MPa para a mesma profundidade no tratamento sem Brachiaria ruziziensis. Por sua vez, Genro Júnior et al. (2004) não observaram nenhum efeito de plantas de cobertura com sistema radicular abundante e formador de poros biológicos na redução da resistência mecânica do solo à penetração.

A prática da rotação de culturas possibilita a diversificação de sistemas radiculares e sua ação sobre o solo. Assim, Abreu et al. (2004), ao avaliarem o efeito da escarificação mecânica (escarificador) e biológica (Crotalaria spectabilis) na redução da compactação de um Argissolo franco-arenoso, constataram que se devem levar em consideração as alterações da umidade e densidade - propriedades usadas como indicadoras da estrutura do solo. Usando o indicador condutividade hidráulica do solo, esses autores observaram maior eficácia da escarificação biológica na ruptura da camada compactada e estabelecimento de poros condutores de água.

No manejo sem escarificação, a taxa de infiltração inicial não foi diferente entre os sistemas de rotação $\mathrm{M} / \mathrm{S} / \mathrm{So}$ e M/S/B (50 e $56 \mathrm{~cm} \mathrm{~h}^{-1}$, respectivamente). Na rotação $\mathrm{M} / \mathrm{S} / \mathrm{B}+\mathrm{Ma}$, a taxa de infiltração inicial foi menor $\left(34 \mathrm{~cm} \mathrm{~h}^{-1}\right)$, comparada à das demais rotações. Para a taxa constante de infiltração, não houve diferença entre as rotações M/S/So e M/S/B+Ma (22 e $20 \mathrm{~cm} \mathrm{~h}^{-1}$, respectivamente), sendo maior na rotação M/S/B (29 cm h-1). A menor infiltração de água pode estar relacionada à compactação que ocorre nos primeiros centímetros do perfil, devido ao efeito cumulativo das pressões exercidas pelo tráfego de máquinas no solo, além da acomodação natural das partículas (Carvalho Jr et al., 1998). O uso continuado da semeadura direta e o uso intensivo da área, seja para a produção de grãos ou cobertura morta, causam redução na macroporosidade e aumento da massa específica e microporosidade do solo, como também observado por Beutler et al. (2001), Tormena et al. (2002) e Secco et al. (2004).

Para a camada de $0,10 \mathrm{~m}$, a taxa de infiltração inicial de água no solo foi maior no sistema escarificado (57 $\mathrm{cm} \mathrm{h}^{-1}$ ), devido ao aumento do sistema poroso promovido pelo revolvimento do solo, comparado ao sistema sem escarificação inicial (46 $\left.\mathrm{cm} \mathrm{h}^{-1}\right)$ (Quadro 1). No solo com escarificação inicial houve diferença significativa entre as rotações, sendo a rotação $\mathrm{M} / \mathrm{S} / \mathrm{B}+\mathrm{Ma}$ maior (91 $\mathrm{cm} \mathrm{h}^{-1}$ ) em relação a M/S/So e M/S/B (32 e $44 \mathrm{~cm} \mathrm{~h}^{-1}$, respectivamente). Isso mostra que o solo nesse sistema apresenta-se com uma camada impeditiva, que dificulta a rápida infiltração da água, e que a maior infiltração inicial na rotação M/S/B+Ma é efeito direto da maior produtividade de matéria seca radicular promovida pelo sistema com Brachiaria ruziziensis + mamona (Quadro 2), que possui sistema radicular mais vigoroso comparado ao sorgo, as quais possibilitaram melhor movimentação da água pelos canais abertos e deixados pelos raízes. No manejo sem escarificação, a taxa de infiltração inicial não foi diferente entre as rotações (46, 47 e $46 \mathrm{~cm} \mathrm{~h}^{-1}$, para M/S/ So, M/S/B e M/S/B+Ma, respectivamente).

A taxa de infiltração constante de água no solo foi maior no sistema escarificado $\left(26 \mathrm{~cm} \mathrm{~h}^{-1}\right)$ comparado ao sistema sem escarificação (16 $\left.\mathrm{cm} \mathrm{h}^{-1}\right)$ (Quadro 2). Houve diferença significativa entre as rotações somente no manejo escarificado, sendo a rotação M/S/ B+Ma maior $\left(34 \mathrm{~cm} \mathrm{~h}^{-1}\right)$ que M/S/So e M/S/B (20 e $23 \mathrm{~cm} \mathrm{~h}^{-1}$, respectivamente). No manejo sem escarificação, a taxa de infiltração constante foi de 15,18 e $15 \mathrm{~cm} \mathrm{~h}^{-1}$, nas rotações M/S/So, M/S/B e M/S/ $\mathrm{B}+\mathrm{Ma}$, respectivamente.

Na camada de $0,20 \mathrm{~m}$, a infiltração inicial de água foi maior quando o solo foi escarificado $\left(85 \mathrm{~cm} \mathrm{~h}^{-1}\right)$, comparada ao manejo sem escarificação $\left(58 \mathrm{~cm} \mathrm{~h}^{-1}\right)$. Isso se deve provavelmente ao rompimento de camadas compactadas, uma vez que a operação de escarificação foi realizada para atingir até $0,30 \mathrm{~m}$ de profundidade.

No manejo sem escarificação inicial foi observado aumento na velocidade de infiltração inicial $\left(58 \mathrm{~cm} \mathrm{~h}^{-1}\right)$, comparada à camada superficial e a 0,10 m (47 e $46 \mathrm{~cm} \mathrm{~h}^{-1}$, respectivamente), e principalmente para a rotação $\mathrm{M} / \mathrm{S} / \mathrm{B}+\mathrm{Ma}\left(78 \mathrm{~cm} \mathrm{~h}^{-1}\right)$, fato que pode ser atribuído a canais deixados pelas raízes das culturas anteriores, que ultrapassaram a camada de maior impedimento $(0,05-0,15 \mathrm{~m})$, sobretudo as da Brachiaria ruziziensis + mamona. Para o tratamento escarificado, na camada de $0,20 \mathrm{~m}$, também se observou a mesma situação, porém com valores mais expressivos (103 $\left.\mathrm{cm} \mathrm{h}^{-1}\right)$, o que está relacionado à influência de Brachiaria ruziziensis sobre os valores iniciais de infiltração.

\section{Segundo ano de experimento}

Na superfície do solo, os valores da velocidade de infiltração de água no solo foram em geral numericamente maiores no manejo sem escarificação, quando comparados aos do manejo de solo escarificado (Quadro 3). No manejo sem escarificação, a rotação $\mathrm{M} / \mathrm{S} / \mathrm{B} / \mathrm{Mi}+\mathrm{B} / \mathrm{B}$ apresentou os maiores valores iniciais $\left(73 \mathrm{~cm} \mathrm{~h}^{-1}\right)$ e constantes $\left(27 \mathrm{~cm} \mathrm{~h}^{-1}\right)$ de velocidade de infiltração. Para o manejo com escarificação, a rotação M/S/B foi a que apresentou menor velocidade de infiltração inicial e constante $\left(16\right.$ e $7 \mathrm{~cm} \mathrm{~h}^{-1}$, respectivamente), sendo a rotação $\mathrm{M} / \mathrm{S} / \mathrm{B}+\mathrm{Ma}$ aquela que mostrou valores mais expressivos (40 e $17 \mathrm{~cm} \mathrm{~h}^{-1}$ ). No segundo ano de experimento houve inversão do comportamento dos tratamentos, fato que era esperado, pois a rotação de culturas promove melhorias em longo prazo nas propriedades físicas do solo, sobretudo na densidade e distribuição do tamanho e número de poros. Isso proporciona taxas de infiltração mais elevadas em relação à semeadura convencional, pois o solo protegido por resíduos vegetais possui proteção 
Quadro 3. Velocidade de infiltração inicial e constante de água em diferentes perfis do solo sob sistemas de manejo do solo e rotação de culturas, em 2007

\begin{tabular}{|c|c|c|c|c|}
\hline \multirow{4}{*}{$\begin{array}{l}\text { Sistema } \\
\text { de rotação }\end{array}$} & \multicolumn{4}{|c|}{$\begin{array}{c}\text { Velocidade de infiltração } \\
\text { de água }\left(\mathrm{cm} \mathrm{h}^{-1}\right)\end{array}$} \\
\hline & \multicolumn{2}{|c|}{ Inicial } & \multicolumn{2}{|c|}{ Constante } \\
\hline & \multicolumn{2}{|c|}{ Escarificação } & \multicolumn{2}{|c|}{ Escarificação } \\
\hline & Com & Sem & Com & Sem \\
\hline & \multicolumn{4}{|c|}{ Superfície } \\
\hline $\mathrm{M} / \mathrm{S} / \mathrm{SO} / \mathrm{Mi} / \mathrm{SO}$ & 36 & 20 & 14 & 11 \\
\hline $\mathrm{M} / \mathrm{S} / \mathrm{B} / \mathrm{Mi}+\mathrm{B} / \mathrm{B}$ & $16 \mathrm{~B}$ & $73 \mathrm{~A}$ & $7 \mathrm{~B}$ & $27 \mathrm{~A}$ \\
\hline $\mathrm{M} / \mathrm{S} / \mathrm{B}+\mathrm{Ma} / \mathrm{Mi}+\mathrm{B} / \mathrm{B}+\mathrm{Ma}$ & 40 & 49 & 17 & 20 \\
\hline \multirow[t]{2}{*}{ Média } & 30 & 47 & 12 & 19 \\
\hline & \multicolumn{4}{|c|}{$0,10 \mathrm{~m}$} \\
\hline $\mathrm{M} / \mathrm{S} / \mathrm{SO} / \mathrm{Mi} / \mathrm{SO}$ & 25 & 19 & 10 & 13 \\
\hline $\mathrm{M} / \mathrm{S} / \mathrm{B} / \mathrm{Mi}+\mathrm{B} / \mathrm{B}$ & 21 & 26 & 10 & 10 \\
\hline $\mathrm{M} / \mathrm{S} / \mathrm{B}+\mathrm{Ma} / \mathrm{Mi}+\mathrm{B} / \mathrm{B}+\mathrm{Ma}$ & 29 & 27 & 10 & 10 \\
\hline \multirow[t]{2}{*}{ Média } & 25 & 24 & 10 & 11 \\
\hline & \multicolumn{4}{|c|}{$0,20 \mathrm{~m}$} \\
\hline $\mathrm{M} / \mathrm{S} / \mathrm{SO} / \mathrm{Mi} / \mathrm{SO}$ & 88 & 39 & 28 & 17 \\
\hline $\mathrm{M} / \mathrm{S} / \mathrm{B} / \mathrm{Mi}+\mathrm{B} / \mathrm{B}$ & 30 & 42 & 11 & 19 \\
\hline $\mathrm{M} / \mathrm{S} / \mathrm{B}+\mathrm{Ma} / \mathrm{Mi}+\mathrm{B} / \mathrm{B}+\mathrm{Ma}$ & 67 & 30 & 15 & 15 \\
\hline Média & 61 & 37 & 18 & 17 \\
\hline
\end{tabular}

(1) M/S/SO/Mi/SO: milheto/soja/sorgo/milho/sorgo; M/S/B/Mi+B/ B: milheto/soja/Brachiaria ruziziensis/milho+Brachiaria/ Brachiaria; M/S/B+Ma/Mi+B/B+Ma: milheto/soja/Brachiaria ruziziensis+mamona/milho + Brachiaria/Brachiaria + mamona. Médias seguidas por letras iguais, maiúsculas na linha e minúsculas na coluna, não diferem entre si pelo teste $t$ (LSD) a $5 \%$.

contra o impacto direto das gotas das chuvas, as quais podem causar compactação superficial no solo (Resck, 1999).

Nas camadas de 0,10 e $0,20 \mathrm{~m}$ não foram observadas diferenças significativas entre os manejos de solo e rotações de culturas (Quadro 3).

As taxas de infiltração de água inicial e constante foram menores na camada de 0,10 m, o que pode estar associado a uma camada impeditiva, que dificulta a infiltração da água. No manejo sem escarificação, a taxa de infiltração inicial foi de 19,26 e $27 \mathrm{~cm} \mathrm{~h}^{-1}$ para as rotações M/S/So/Mi/So, M/S/B/Mi+B/B e M/S/ $\mathrm{B}+\mathrm{Ma} / \mathrm{Mi}+\mathrm{B} / \mathrm{B}+\mathrm{Ma}$, respectivamente (Quadro 3). No manejo com escarificação, os valores de infiltração inicial foram de 25,21 e $29 \mathrm{~cm} \mathrm{~h}^{-1}$ para as rotações $\mathrm{M} / \mathrm{S} / \mathrm{So} / \mathrm{Mi} / \mathrm{So}, \mathrm{M} / \mathrm{S} / \mathrm{B} / \mathrm{Mi}+\mathrm{B} / \mathrm{B}$ e $\mathrm{M} / \mathrm{S} / \mathrm{B}+\mathrm{Ma} / \mathrm{Mi}+\mathrm{B} /$ $\mathrm{B}+\mathrm{Ma}$, respectivamente. Os valores de infiltração foram de 13, 10 e $10 \mathrm{~cm} \mathrm{~h}^{-1}$ para o solo sem escarificação e de 10,10 e $10 \mathrm{~cm} \mathrm{~h}^{-1}$ no solo com escarificação, para as rotações M/S/So/Mi/So, M/S/B/Mi+B/B e M/S/B+Ma/ $\mathrm{Mi}+\mathrm{B} / \mathrm{B}+\mathrm{Ma}$, respectivamente.

$\mathrm{Na}$ camada de 0,20 m, as taxas de infiltração de água inicial e constante no manejo com escarificação foram numericamente maiores para a rotação
M/S/So/Mi/So (88 e $28 \mathrm{~cm} \mathrm{~h}^{-1}$, respectivamente). Em contrapartida, para o manejo escarificado, as taxas de infiltração de água inicial e constante no manejo sem escarificação foram numericamente maiores para a rotação M/S/B/Mi+B/B (42 e $19 \mathrm{~cm} \mathrm{~h}^{-1}$, respectivamente).

Ao comparar os resultados do primeiro ano com os do segundo, observa-se inversão dos resultados obtidos quando os anéis foram instalados na camada superficial do solo. Na primeira safra, a velocidade de infiltração de água foi maior nos tratamentos com escarificação inicial, comparados aos mesmos tratamentos sem escarificação. Isso pode ser explicado, em parte, pela maior massa de matéria seca da parte aérea e radicular apresentada por todos os manejos de solo e rotações de culturas no segundo ano (Quadro 4). Contudo, vale ressaltar que as rotações com Brachiaria e Brachiaria + mamona foram as que proporcionaram resultados mais expressivos de produção de massa aérea e radicular.

Ao comparar os resultados a $0,10 \mathrm{~m}$ do primeiro ano com os do segundo para o solo escarificado, observase que a taxa de infiltração inicial de água foi maior no primeiro ano $\left(57 \mathrm{~cm} \mathrm{~h}^{-1}\right)$ em relação ao segundo $\left(25 \mathrm{~cm} \mathrm{~h}^{-1}\right)$. No solo sem escarificação, no primeiro ano a taxa foi de $46 \mathrm{~cm} \mathrm{~h}^{-1} \mathrm{e}$, no segundo, de $24 \mathrm{~cm} \mathrm{~h}^{-1}$.

Quadro 4. Produtividade de matéria seca da parte aérea e radicular de plantas de cobertura, em 2007

\begin{tabular}{|c|c|c|c|}
\hline \multirow{2}{*}{$\begin{array}{l}\text { Sistema } \\
\text { de rotação(1) }\end{array}$} & \multicolumn{2}{|c|}{ Escarificação } & \multirow{2}{*}{ Média } \\
\hline & Com & Sem & \\
\hline \multicolumn{4}{|c|}{ Massa de matéria seca da parte aérea $\left(\mathrm{kg} \mathrm{ha}^{-1}\right)$} \\
\hline M/S/SO/Mi/SO & $3050 \mathrm{~b}$ & $3296 \mathrm{~b}$ & \\
\hline $\mathrm{M} / \mathrm{S} / \mathrm{B} / \mathrm{Mi}+\mathrm{B} / \mathrm{B}$ & $4480 \mathrm{a}$ & $5404 \mathrm{a}$ & $4942 \mathrm{a}$ \\
\hline $\mathrm{M} / \mathrm{S} / \mathrm{B}+\mathrm{Ma} / \mathrm{Mi}+\mathrm{B} / \mathrm{B}+\mathrm{Ma}$ & $6559 \mathrm{a}$ & $5659 \mathrm{a}$ & $6109 \mathrm{a}$ \\
\hline Média & 4696 & 4786 & - \\
\hline \multicolumn{4}{|c|}{$\begin{array}{l}\text { Massa de matéria seca radicular }\left(\mathrm{kg} \mathrm{ha}^{-1}\right) \\
0,00-0,05 \mathrm{~m}\end{array}$} \\
\hline M/S/SO/Mi/SO & $300 \mathrm{~b}$ & $90 \mathrm{~b}$ & $195 \mathrm{~b}$ \\
\hline $\mathrm{M} / \mathrm{S} / \mathrm{B} / \mathrm{Mi}+\mathrm{B} / \mathrm{B}$ & $735 \mathrm{a}$ & $600 \mathrm{a}$ & $670 \mathrm{a}$ \\
\hline $\mathrm{M} / \mathrm{S} / \mathrm{B}+\mathrm{Ma} / \mathrm{Mi}+\mathrm{B} / \mathrm{B}+\mathrm{Ma}$ & 785 a & $750 \mathrm{a}$ & 770 a \\
\hline Média & 605 & 480 & \\
\hline \multicolumn{4}{|c|}{$0,05-0,10 \mathrm{~m}$} \\
\hline $\mathrm{M} / \mathrm{S} / \mathrm{SO} / \mathrm{Mi} / \mathrm{SO}$ & $95 \mathrm{~b}$ & $70 \mathrm{~b}$ & $83 \mathrm{~b}$ \\
\hline $\mathrm{M} / \mathrm{S} / \mathrm{B} / \mathrm{Mi}+\mathrm{B} / \mathrm{B}$ & $555 \mathrm{a}$ & $675 \mathrm{a}$ & $615 \mathrm{a}$ \\
\hline $\mathrm{M} / \mathrm{S} / \mathrm{B}+\mathrm{Ma} / \mathrm{Mi}+\mathrm{B} / \mathrm{B}+\mathrm{Ma}$ & 565 a & $715 \mathrm{a}$ & $640 \mathrm{a}$ \\
\hline Média & 405 & 485 & - \\
\hline \multicolumn{4}{|c|}{$0,10-0,20 \mathrm{~m}$} \\
\hline $\mathrm{M} / \mathrm{S} / \mathrm{SO} / \mathrm{Mi} / \mathrm{SO}$ & $120 \mathrm{~b}$ & $90 \mathrm{~b}$ & $105 \mathrm{~b}$ \\
\hline $\mathrm{M} / \mathrm{S} / \mathrm{B} / \mathrm{Mi}+\mathrm{B} / \mathrm{B}$ & $420 \mathrm{a}$ & $440 \mathrm{a}$ & $430 \mathrm{a}$ \\
\hline $\mathrm{M} / \mathrm{S} / \mathrm{B}+\mathrm{Ma} / \mathrm{Mi}+\mathrm{B} / \mathrm{B}+\mathrm{Ma}$ & $440 \mathrm{a}$ & $380 \mathrm{a}$ & 410 a \\
\hline Média & 330 & 300 & - \\
\hline
\end{tabular}

(1) M/S/SO/Mi/SO: milheto/soja/sorgo/milho/sorgo; M/S/B/Mi+B/ B: milheto/soja/Brachiaria ruziziensis/milho+Brachiaria/ Brachiaria; M/S/B+Ma/Mi+B/B+Ma: milheto/soja/Brachiaria ruziziensis+mamona/milho + Brachiaria/Brachiaria + mamona. Médias seguidas por letras iguais, maiúsculas na linha e minúsculas na coluna, não diferem entre si pelo teste $\mathrm{t}$ (LSD) a $5 \%$. 
Para a camada de $0,20 \mathrm{~m}$, a infiltração inicial no primeiro ano em solo escarificado foi numericamente maior $\left(85 \mathrm{~cm} \mathrm{~h}^{-1}\right)$ comparada à do segundo ano $\left(61 \mathrm{~cm} \mathrm{~h}^{-1}\right)$. No solo sem escarificação, as taxas foram de 58 e $37 \mathrm{~cm} \mathrm{~h}^{-1}$ para primeiro e segundo anos, respectivamente.

De maneira geral, os valores de taxa de infiltração de água no solo, tanto inicial quanto constante, foram altos em todos os tratamentos. Isso é explicado principalmente pelo baixo teor de umidade do solo no momento de realização dos testes de infiltração (150 $\left.\mathrm{g} \mathrm{kg}^{-1}\right)$, bem como pelo método utilizado (cilindros concêntricos), o qual pressupõe uma carga hidráulica ocasionada pela lâmina de água sobre o solo durante a execução dos testes de infiltração. Assim, em função da carga hidráulica, as taxas de infiltração apresentadas nos quadros 1 e 3 podem estar superestimadas em relação à taxa real de infiltração de água no solo (Forsythe, 1975; Figueiredo et al., 2000).

\section{CONCLUSSÕES}

1. O manejo do solo com escarificação proporciona maior infiltração de água no solo apenas no primeiro ano de trabalho.

2. A atividade do sistema radicular das espécies nas parcelas sem escarificação aumentou a velocidade de infiltração da água no solo.

3. Independentemente do solo escarificado ou não, a rotação de culturas envolvendo Brachiaria ruziziensis + mamona resultou em maior infiltração de água no solo.

\section{LITERATURA CITADA}

ABREU, S.L.; REICHERT, J.M. \& REINERT, D.J. Escarificação mecânica e biológica para a redução da compactação em Argissolo Franco-Arenoso sob plantio direto. R. Bras. Ci. Solo, 28:519-531, 2004.

BENJAMIN, J.G. Tillage effects on near-surface soil hydraulic properties. Soil Till. Res., 26:277-288, 1993.

BERTOL, I.; BEUTLER, J.F.; LEITE, D. \& BATISTELA, O. Propriedades físicas de um Cambissolo Húmico afetadas pelo tipo de manejo do solo. Sci. Agric., 58:555-560, 2001.

BEUTLER, A.N.; SILVA, M.L.N.; CURI, N.; FERREIRA, M.M.; CRUZ, J.C. \& PEREIRA FILHO, I.A. Resistência à penetração e permeabilidade de Latossolo Vermelho distrófico típico sob sistemas de manejo na região dos cerrados. R. Bras. Ci. Solo, 25:167-177, 2001.

BORGES, E.N.; LOMBARDI NETO, F.; CORRÊA, G.F. \& BORGES, E.V.S. Alterações físicas introduzidas por diferentes níveis de compactação em Latossolo VermelhoEscuro textura média. Pesq. Agropec. Bras., 34:1663-1667, 1999.
CAMARA, R.K. \& KLEIN, V.A. Propriedades físico-hídricas do solo sob plantio direto escarificado e rendimento da soja. Ci. Rural, 35:813-819, 2005 .

CAMARA, R.C. \& KLEIN, V.A. Escarificação em plantio direto como técnica de conservação do solo e da água. R. Bras. Ci. Solo, 29:789-796, 2005b.

CARVALHO Jr., O.S.; GASCÓ, J.M.; LOPEZ, F.G. \& REQUEJO, A.S. Variabilidade espacial de algumas propriedades químicas e físicas de um solo submetido a diferentes sucessões de cultivo. R. Bras. Ci. Solo, 22:497503,1998

CHANG, C. \& LINDWALL, C.W. Effects of tillage and crop rotation on physical properties of a loam soil. Soil Till. Res., 22:383-389, 1992.

CUNHA, E.Q.; BALBINO, L.C.; LEANDRO, W.M.; STONE, L.F.; ALVES, H.M. \& SEVERIANO, E.C. Resistência mecânica do solo à penetração afetada pela presença de Brachiaria ruziziensis em sistemas de rotação de culturas. In: REUNIÃO BRASILEIRA DE MANEJO E CONSERVAÇÃO DE SOLO E ÁGUA, 15., Santa Maria, 2004. Anais... Santa Maria, 2004. CD-ROM.

DE MARIA, I.C.; CASTRO O.M. \& SOUZA DIAS, H. Atributos físicos do solo e crescimento radicular de soja em Latossolo Roxo sob diferentes métodos de preparo do solo. R. Bras. Ci. Solo, 23:703-709, 1999.

DERPSCH, R.; ROTH, C.; SIDIRAS, N. \& KÖPKE, U. Controle de erosão no Paraná, Brasil: Sistemas de cobertura do solo, plantio direto e preparo conservacionista do solo. Eschborn, Deutsche Gesellschaff für Technische Zusammenarbeit, 1991. 272p.

DIAS JÚNIOR, M.S. \& PIERCE, F.J. O processo de compactação do solo e sua modelagem. R. Bras. Ci. Solo, 20:175-182, 1996.

FIGUEIREDO, L.H.A.; DIAS JUNIOR, M.S. \& FERREIRA, M.M. Umidade crítica de compactação e densidade do solo máxima em resposta a sistemas de manejo num Latossolo Roxo. R. Bras. Ci. Solo, 24:487-493, 2000.

FORSYTHE, W. Física de suelos: Manual de laboratorio. San José, Internacional de Ciencias Agrícolas, 1975. 209p.

GENRO JUNIOR, S.A.; REINERT, D.J. \& REICHERT, J.M. Variabilidade temporal da resistência à penetração de um Latossolo argiloso sob semeadura direta com rotação de culturas. R. Bras. Ci. Solo, 28:477-484, 2004.

HORN, R.; WAY, T. \& ROSTEK, J. Effect of repeated tractor wheeling on stress/strain properties and consequences on physical properties in structured arable soils. Soil Till. Res., 73:101-106, 2003.

JORGE, J.A. Física e manejo dos solos tropicais. Campinas, Instituto Campineiro de Ensino Agrícola, 1985. p.89-118.

KOSTIAKOV, A.N. On the dynamics of the coefficient of waterpercolation in soils and on the necessity for studying it from a dynamic point of view for purposes of amelioration. In: INTERNATIONAL SOIL SCIENCE CONGRESS, 6. Paris; 1931. Anais. Paris, International Soil Science Society, 1932. p.17-21. 
LAL, R. \& VANDOREN, D. Influence of 25 years of continuous corn production by three tillage methods on water infiltration of two soils in Ohio. Soil Till. Res., 16:71-74, 1990.

LANZANOVA, M.E.; NICOLOSO, R.S.; LOVATO, T.; ELTZ, F.L.F.; AMADO, T.J.C. \& REINERT, D.J. Atributos físicos do solo em sistemas de integração lavoura-pecuária sob plantio direto. R. Bras. Ci. Solo, 31:1131-1140, 2007.

MORAES, M.H.; BENEZ, S.H. \& LIBARDI, P.L. Efeitos da compactação em algumas propriedades físicas do solo e seu reflexo no desenvolvimento das raízes de plantas de soja. Bragantia, 54:393-403, 1995.

MÜLLER, M.M.L.; CECCON, G. \& ROSOLEM, C.A. Influência da compactação do solo em subsuperfície sobre o crescimento aéreo e radicular de plantas de adubação verde de inverno. R. Bras. Ci. Solo, 25:531-538, 2001.

RESCK, D.V.S. O plantio direto como alternativa de sistema de manejo e conservação do solo e da água na região dos cerrados. In: CONGRESSO BRASILEIRO DE CIÊNCIA DO SOLO, 27., Brasília, 1999. Resumo expandido. Brasília, Sociedade Brasileira de Ciência do Solo, 1999. CD-ROM.

ROSOLEM, C.A.; VALE, L.S.R.; GRASSI FILHO, H. \& MORAES, M.H. Sistema radicular e nutrição do milho em função da calagem e da compactação do solo. R. Bras. Ci. Solo, 18:491-497, 1994.

SANTOS, G.; JACOMINE, P.K.T.; ANJOS, L.H.C.; OLIVEIRA, V.A.; OLIVEIRA, J.B.; COELHO, M.R.; LUMBRERAS, J.F. \& CUNHA, T.J.F. Sistema brasileiro de classificação de solos. Rio de Janeiro, Embrapa Solos, 2006. 306p.

SECCO, D.; REINERT, D.J.; REICHERT, J.M. \& DA ROS, C.O. Produtividade de soja e propriedades físicas de um Latossolo submetido a sistemas de manejo e compactação. R. Bras. Ci. Solo, 28:797-804, 2004.
SÉGUY, L. \& BOUZINAC, S. O plantio direto no cerrado úmido. Piracicaba, Instituto da Potassa e Fosfato, 1995. p.1-2. (Informações Agronômicas, 69)

SIDIRAS, N.; HENKLAIN, J.C. \& DERPSCH, R. Comparison of three different tillage systems with respect to some physical properties, the soil and water conservation and the yields of soybean and wheat on an Oxisol. Zeitschrift Acker-und Pflanzenbau, 151:137-148, 1982.

SILVA, R.H. \& ROSOLEM, C.A. Crescimento radicular de soja em razão da sucessão de cultivos e da compactação do solo. Pesq. Agropec. Bras., 37:855-860, 2002.

SILVA, V.R.; REINERT, D.J. \& REICHERT, J.M. Fatores controladores da compressibilidade de um Argissolo Vermelho-Amarelo distrófico arênico e de um Latossolo Vermelho distrófico típico. II - Grau de saturação em água. R. Bras. Ci. Solo, 26:9-15, 2002.

STONE, L.F. \& SILVEIRA, P.M. Efeitos do sistema de preparo e da rotação de culturas na porosidade e densidade do solo. R. Bras. Ci. Solo, 25:395-401, 2001.

TAVARES FILHO, J. \& TESSIER, D. Influence des pratiques culturales sur le comportement et les propriétés de sols du Paraná (Brésil). Étude Gestion Sols, 5:61-71, 1998.

TORMENA, C.A.; BARBOSA, M.C.; COSTA, A.C.S. \& GONÇALVES, A.C.A. Densidade, porosidade e resistência à penetração em Latossolo cultivado sob diferentes sistemas de preparo do solo. Sci. Agric., 59:795-801, 2002.

VERNETTI JUNIOR, F.J. \& GOMES, A.S. Plantio direto: Uma opção de manejo para a produção agrícola sustentável. Pelotas, Embrapa Clima Temperado, 1999. 69p. (Embrapa Clima Temperado. Documentos, 58) 